\title{
Parameter Optimization and Prediction Model of Induction Heating for Large-Diameter Pipe
}

\author{
Xiurong Fang $(\mathbb{D}$, Jia Lu, Junfeng Wang, and Jinhui Yang \\ School of Mechanical Engineering, Xian University of Science and Technology, Xian 710054, China \\ Correspondence should be addressed to Xiurong Fang; fangxr098@163.com
}

Received 26 July 2018; Revised 6 October 2018; Accepted 1 November 2018; Published 26 November 2018

Guest Editor: Arshad Afzal

Copyright (C) 2018 Xiurong Fang et al. This is an open access article distributed under the Creative Commons Attribution License, which permits unrestricted use, distribution, and reproduction in any medium, provided the original work is properly cited.

\begin{abstract}
The parameters of induction heating of large-diameter pipes have a direct effect on the final processing quality of the elbow, and the complexity of multifield coupling of magnetothermal force in induction heating can make it impossible to quantitatively optimize the design parameters of the induction heating device. In this paper, X80 pipeline steel induction heating is taken as the research object, and a corresponding numerical model is established. The influence of induction heating process parameters on the heating temperature of pipeline steel under the skin effect is determined. First, the influence of process parameters on the heating effect of pipeline steel is quantified by orthogonal test. Then, taking the optimum temperature difference between the inner and outer wall of X80 pipeline steel during the induction heating process as a target, the optimal process parameter set of the pipe induction heating is determined by using neural network genetic algorithm. Finally, comparing the relevant test criteria of the regression equation, the optimum mathematical prediction model of the outer wall temperature of the pipe induction heating process is obtained, which provides a theoretical basis for optimization of the process parameters of the pipe-based induction heating device.
\end{abstract}

\section{Introduction}

The induction heating of pipe is one of the common techniques for production of elbows thanks to its rapid heating, easy cooling, small thinning rate of wall thickness, and easy adjustment of the bending radius of elbow. In the actual project of oil and gas transmission engineering, the bending of large-diameter pipes in oil and gas transportation pipe network is mostly processed by hydraulic push-type induction heating pipe bending machine. The system diagram is shown in Figure 1 [1], and the specific induction heating diagram is shown in Figure 2 [2]. It is required to realize continuous operation of propulsion $\longrightarrow$ heating $\longrightarrow$ bending $\longrightarrow$ cooling $\longrightarrow$ forming while the induction heating device fulfills the local heating of the pipe when the pipe bending machine is working [3]. At present, many researchers have conducted a lot of studies on the bending process of different materials, the mechanical properties, and the microstructure of the bent pipe [4-7]. However, the influence of various parameters on the heating effect of the induction heating forming process for large-diameter pipe is not yet clear. The detailed theoretical guidance and basis for the selection and optimization of design parameters on the induction heating device are not yet available. Thus, it is impossible to ensure a reasonable matching between the heating time of the pipe and the pushing speed of the hydraulic cylinder, resulting in the fact that the reliability of the pipe quality cannot be guaranteed [8]. Therefore, the induction heating device of the pipe has become one of the important factors affecting the final processing quality of the elbow. In this paper, the optimization of the process parameters of pipe induction heating is investigated by means of numerical simulation and mathematical methods.

\section{Analysis on Induction Heating Parameters of Pipes}

The basic principle of induction heating is shown in Figure 3: the coil is connected to the heating power source, and an alternating magnetic field is generated in the pipe when the alternating current in the heating power source flows 


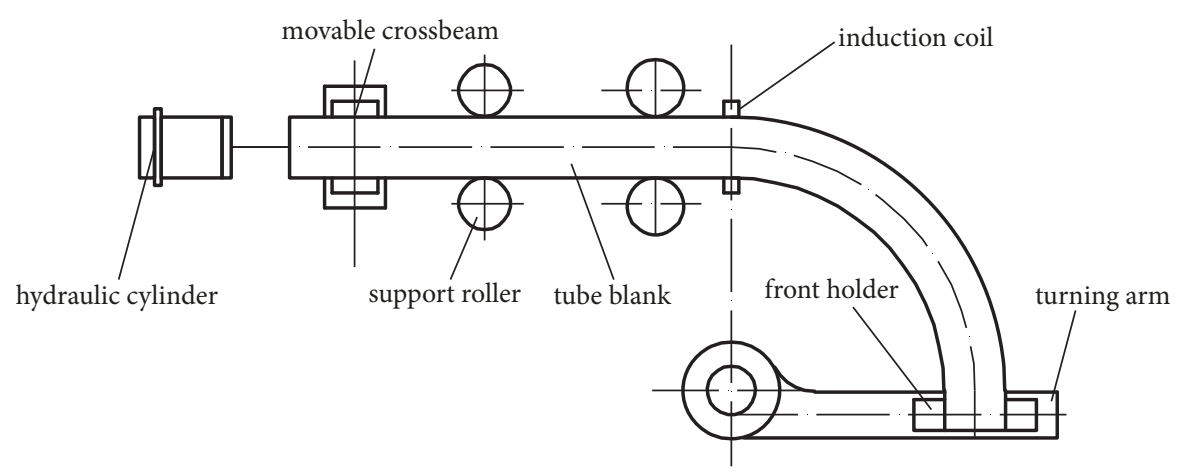

FIGURE 1: Structure of the bend of induction heating pipe bending machine.

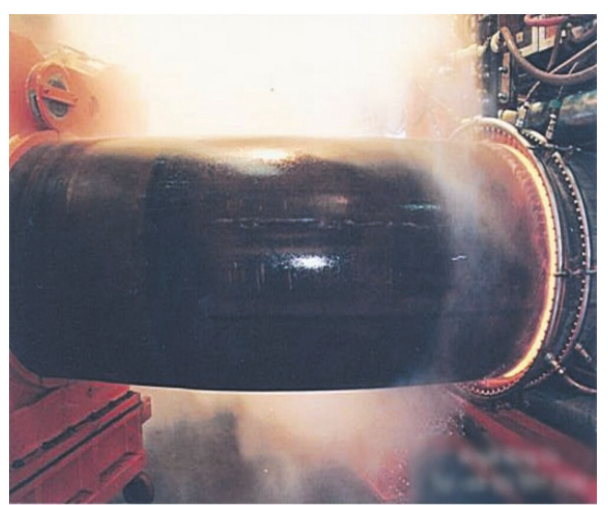

FIGURE 2: Specific induction heating.

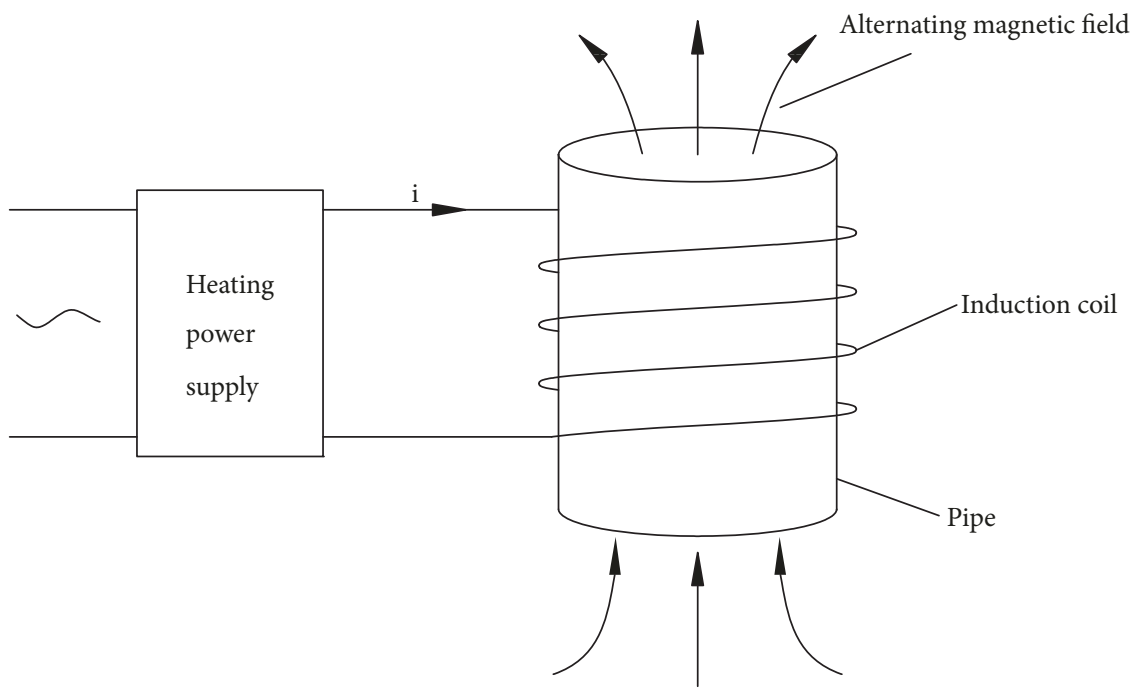

FIGURE 3: Schematic diagram of pipe induction heating.

through the coil. Under the action of the alternating magnetic field, vortex current is generated inside the pipe, and the vortex current and alternating current in the induction coil have opposite directions with the same frequency. When the vortex current passes through the pipe, the pipe generates a large amount of Joule heat under the action of the material resistance, so that the pipe temperature rises rapidly to achieve the purpose of heating [9].

It can be seen that electromagnetic induction is used to generate vortex current heating in the conductor to realize the heating of the work piece. Therefore, by the electromagnetic induction law (1), the Joule-Electric law (2), and technical 
requirements of the large-diameter pipe induction heating forming device, we can obtain the main influential factors on the heating effect of the pipe, such as the induction frequency, current density, and air gap [10].

$$
\begin{gathered}
e=-N \frac{d \Phi}{d t} \\
Q=0.24 i^{2} R t
\end{gathered}
$$

where $N$ is the number of turns of the induction coil; $Q$ is Joule heat (unit is $J$ ); $i$ is the effective value of induction current (unit is $A$ ); $R$ is conductor resistance (unit is $\Omega$ ); and $t$ is the time of the current flowing through the conductor (unit is $s$ ).

Taking the elbow forming of X80 pipeline steel [11] with diameter $\Phi 1219 \mathrm{~mm}$ and wall thickness $\delta 27 \mathrm{~mm}$ as an example, the numerical modeling of induction heating is carried out.

\subsection{Mathematical Model of Induction Heating Electromagnetic} Field. In the numerical calculation of finite element, the mathematical model of the induction heating vortex current field for the heated workpiece area can be obtained by the control equation (Maxwell equations) and the magnetic vector-scalar potential $\overrightarrow{(A}-\Phi)$ theory of the induction heating electromagnetic field [12-14]:

$$
\begin{aligned}
& \nabla \times \frac{1}{\mu} \nabla \times \vec{A}-\nabla \frac{1}{\mu}(\nabla \cdot \vec{A})+\sigma \frac{\partial \vec{A}}{\partial t}+\sigma \nabla \Phi=0 \\
& \nabla^{2} \Phi+\frac{\partial}{\partial t}(\nabla \cdot \vec{A})=0 \\
& \overrightarrow{J_{e}}=-\sigma \frac{\partial \vec{A}}{\partial t}-\sigma \nabla \Phi
\end{aligned}
$$

where $\nabla$ is Hamilton operator; $\mu$ is magnetic conductivity $(H / m) ; \sigma$ is material conductivity $(\mathrm{S} / \mathrm{m}) ; \varepsilon$ is capacitivity $(\mathrm{F} / \mathrm{m}) ; \vec{A}$ is magnetic vector potential; $\Phi$ is scalar potential; and $\vec{J}_{e}$ is induction vortex current density vector $\left(\mathrm{A} / \mathrm{m}^{2}\right)$.

In order to ensure the continuity condition of the field quantity at the interface of different media, consider the boundary condition as a ferromagnetic boundary with surface current density $\vec{J}$. The expression is shown as

$$
\vec{n} \times\left(\frac{1}{\mu} \nabla \times \vec{A}\right)=-\vec{J}
$$

\subsection{Mathematical Model of Induction Heating Temperature} Field. It is assumed that the Joule heat generated by the vortex current in the alternating magnetic field is completely converted into its own heat; that is, the induced current Joule heat obtained by the electromagnetic field is used as an internal heat source to heat the workpiece, and the heating process is an unsteady heat conduction process $[15,16]$. Based on Fourier's law and the first law of thermodynamics [17], the differential form of the transient temperature field governing equation in induction heating can be derived:

$$
\begin{gathered}
\rho c \frac{\partial T}{\partial t}-\frac{\partial}{\partial x}\left(\lambda_{x} \frac{\partial T}{\partial x}\right)-\frac{\partial}{\partial y}\left(\lambda_{y} \frac{\partial T}{\partial y}\right)-\frac{\partial}{\partial z}\left(\lambda_{z} \frac{\partial T}{\partial z}\right) \\
-q_{v}=0
\end{gathered}
$$

where $\lambda$ is thermal conductivity $\left(\mathrm{W} /\left(\mathrm{m} \cdot{ }^{\circ} \mathrm{C}\right)\right) ; T$ is temperature field distribution function; $q_{v}$ is intensity of the heat source of induction vortex current in the pipeline $\left(\mathrm{W} / \mathrm{m}^{3}\right) ; \rho$ is material density $\left(\mathrm{Kg} / \mathrm{m}^{3}\right)$; $c$ is the specific heat capacity of material $(J /(K g \cdot K))$.

Use the Newton convection boundary as a temperature boundary condition:

$$
-\lambda \frac{\partial T}{\partial n}=h\left(T-T_{0}\right)
$$

where $n$ refers to the normal direction on the boundary; $\lambda$ is thermal conductivity $\left(\mathrm{W} / \mathrm{m} \cdot{ }^{\circ} \mathrm{C}\right) ; h$ is convective heat transfer coefficient $\left(\mathrm{W} / \mathrm{m}^{2} \cdot \mathrm{K}\right)$; $T$ is work surface temperature $(\mathrm{K})$; and $T_{0}$ indicates ambient temperature $(\mathrm{K})$.

2.3. Coupling of Induction Heating Electromagnetic FieldTemperature Field. The induction heating is involved in the interaction of two physical fields of electromagnetic field and temperature field. The complexity of solving the magnetothermal coupling problem makes it difficult to obtain accurate solutions for many engineering issues [18]. Hopefully, the large-scale finite element numerical simulation software can be used for engineers to solve complex problems on the basis of theoretical analysis. This paper is aimed at the characteristics of induction heating magneto-thermal coupling of large-diameter pipes. We adopt ABAQUS software to solve the magneto-thermal coupling issue by sequential coupling [19]. First, the vortex current is obtained in the electromagnetic field; then the Joule heat of the workpiece under the action of vortex current field is got. Eventually, the Joule heat is used as the temperature field input condition to obtain the temperature distribution on the workpiece. The analysis process of magnetothermal coupling during the induction heating is shown in Figure 4.

2.4. Building of Numerical Model. The geometric model of pipe induction heating consists of three parts: $X 80$ pipe, induction coil, and air. Since the pipe is only involved in the solution of temperature field, it is assumed that, in the solution of the electromagnetic field, the physical properties of the material corresponding to the induction coil and air are not affected by the temperature change. Since the $X 80$ pipe, induction coil and air together constitute the electromagnetic path in the induction heating process, the thermal property parameters of the relative magnetoconductivity, resistivity, specific heat capacity, thermal conductivity, density, etc. corresponding to the three parts should be considered in solving the electromagnetic field (as shown in Table 1). The material of induction coil is T3 copper, its resistivity is $1.75 \times$ $10^{-8} \Omega \bullet \mathrm{m}$, and the relative magneto-conductivity is 1 . As air is 
TABLE 1: The thermal properties of $X 80$.

\begin{tabular}{|c|c|c|c|c|c|c|}
\hline $\begin{array}{l}\text { Temperature } \\
\left({ }^{\circ} \mathrm{C}\right)\end{array}$ & $\begin{array}{c}\text { Relative } \\
\text { Permeability } \mu \\
\end{array}$ & $\begin{array}{c}\text { Resistivity } \rho \\
\left(10^{-6} \Omega \cdot \mathrm{m}\right)\end{array}$ & $\begin{array}{c}\text { Specific Heat } C_{p} \\
\left(\mathrm{~J} / \mathrm{Kg} .{ }^{\circ} \mathrm{C}\right)\end{array}$ & $\begin{array}{c}\text { Thermal Conductivity } \\
K\left(\mathrm{~W} / \mathrm{m} \cdot{ }^{\circ} \mathrm{C}\right)\end{array}$ & $\begin{array}{c}\text { Density } \\
\rho\left(\mathrm{Kg} / \mathrm{m}^{3}\right) \\
\end{array}$ & $\begin{array}{c}\text { Emissivity } \\
C_{s}\left(J / \mathrm{m}^{2} \mathrm{sK}^{4}\right) \\
\end{array}$ \\
\hline 0 & 200 & 0.195 & 450 & 47.4 & 7896 & 1 \\
\hline 25 & 198 & 0.202 & 450 & 46.2 & 7896 & 0.998 \\
\hline 100 & 194 & 0.251 & 479 & 43.7 & 7870 & 0.996 \\
\hline 200 & 186 & 0.336 & 520 & 40.3 & 7849 & 0.992 \\
\hline 300 & 179 & 0.434 & 564 & 38 & 7824 & 0.987 \\
\hline 400 & 167 & 0.539 & 612 & 35.9 & 7796 & 0.983 \\
\hline 500 & 156 & 0.659 & 668 & 33.8 & 7769 & 0.978 \\
\hline 600 & 139 & 0.792 & 785 & 31.7 & 7744 & 0.978 \\
\hline 700 & 93 & 0.947 & 936 & 28.4 & 7716 & 0.879 \\
\hline 800 & 1 & 1.073 & 848 & 25.9 & 7691 & $0 / 648$ \\
\hline 900 & 1 & 1.164 & 655 & 23.5 & 7665 & 0.594 \\
\hline 1000 & 1 & 1.199 & 620 & 23.9 & 7639 & 0.535 \\
\hline
\end{tabular}

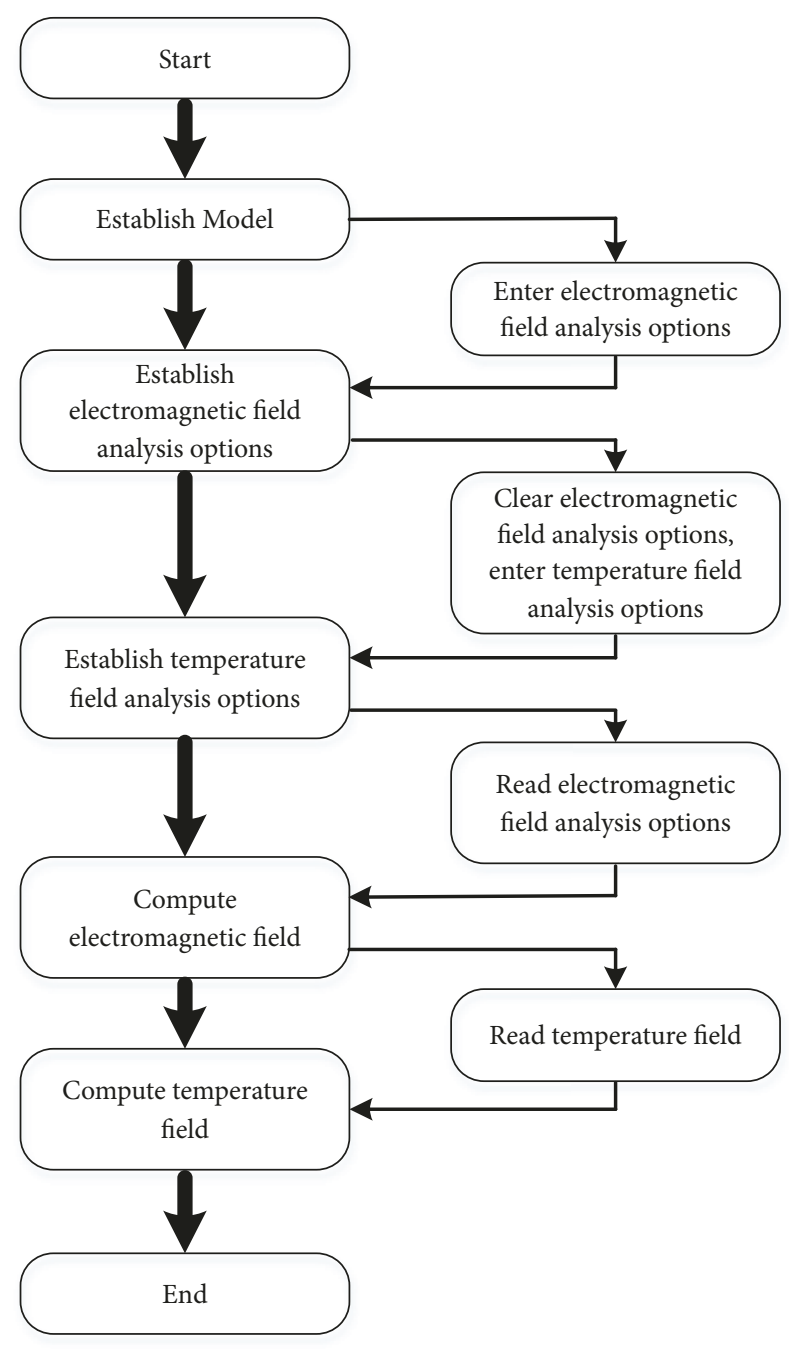

FIGURE 4: Analysis process of magnetothermal coupling during the induction heating. not affected by the current, the relative magnetoconductivity should be set as 1 when performing numerical simulation.

It is one of the important influential factors on the quality of the pipe to reasonably match the heating time of the pipe and the pushing speed of the hydraulic cylinder during the bending process of the large-diameter pipe (see Figure 1). Thus, in order to further study the problem of matching the induction heating time with the pushing speed, the finite element model is built in Cartesian coordinate system. At the same time, considering that the large-diameter pipe and its applied load are axisymmetric, 1/4 of the pipe is used to build a finite element model. The working loads are applied to the model according to the characteristics of each physical field; the corresponding analysis steps, solution variables, and boundary conditions are setup; different grid types are selected to mesh the model (the unit type of EMC3D8 is selected in the electromagnetic field and the unit type of DC3D8 is selected in the temperature field). In order to ensure the accuracy and convergence of the calculation, the pipe mesh is refined, as shown in Figure 5.

\section{Results Analysis}

3.1. Analysis of Numerical Simulation Results. In order to visually display the dynamic changes of the electromagnetic field and temperature field inside the pipe during the heating process, the main parameters such as current frequency $(f=1000 \mathrm{~Hz})$, current density $\left(J=6 \times 10^{7} \mathrm{~A} / \mathrm{m}^{2}\right)$, and air gap $(d=30 \mathrm{~mm})$ are determined according to the engineering practice, and the distribution clouds of the Joule heat and temperature of the pipe under induction heating are obtained through simulation (see Figures 6 and 7), and the curves of temperature for the inner and outer wall of the pipe with the times are shown in Figure 8. It can be seen that the distribution of Joule heat and temperature on the pipe is that the outer wall's is much greater than that of the inner wall due 


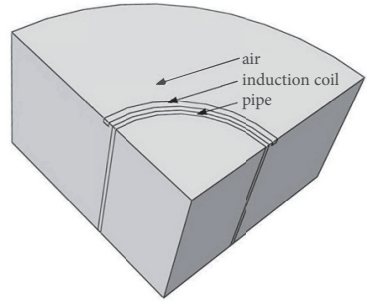

(a)

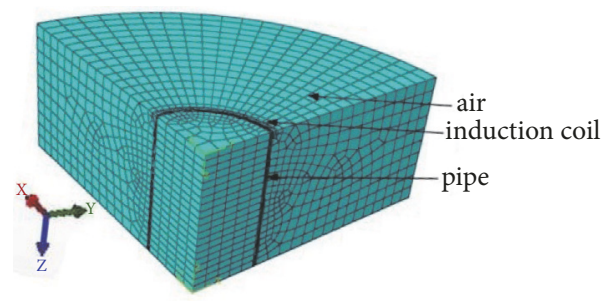

(b)

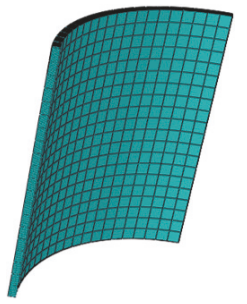

(c)

FIGURE 5: Numerical model of induction heating for thin-walled pipe. (a) Geometric model. (b) Finite element model. (c) Finite element model of the pipe.

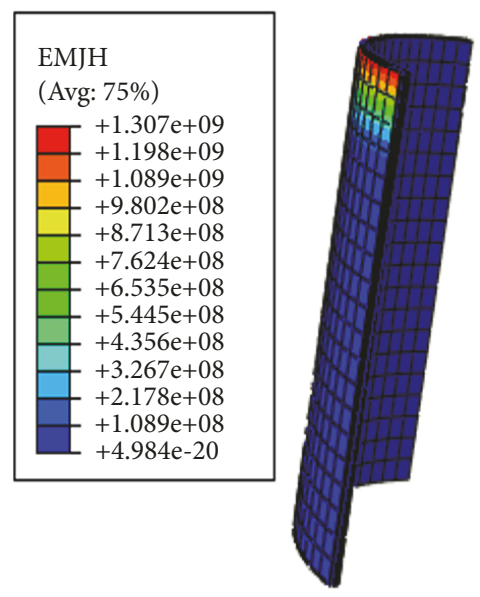

FIGURE 6: Distribution cloud of Joule heat in pipe (Unit: $J$ ).

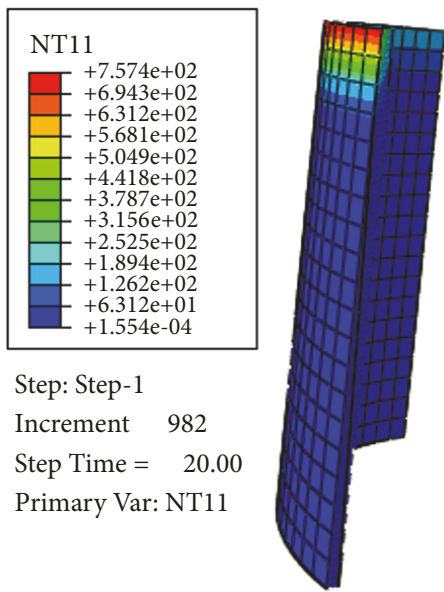

FIGURE 7: Distribution cloud of temperature in pipe (Unit: $\left.{ }^{\circ} \mathrm{C}\right)$.

to the effects of skin effect, proximity effect, and ring effect in the induction heating process [20], which ultimately leads to the greater temperatures difference of the inner and outer walls of the pipe, causing a great inconvenience to the pushing speed of the elbow, which in turn affects the quality of the pipe bending.

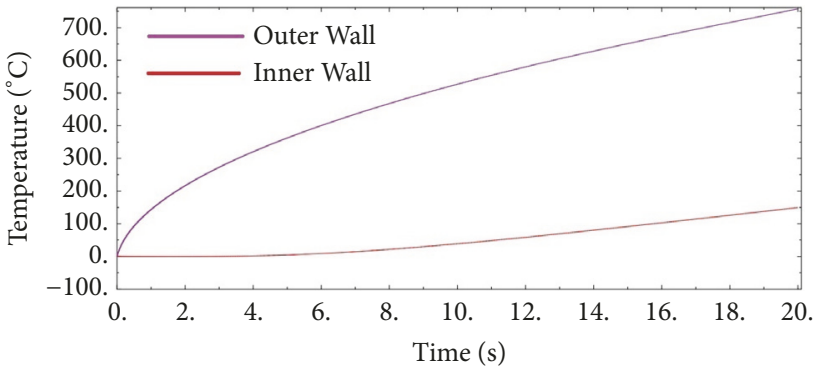

FIGURE 8: Temperature curves of the inner and outer wall of pipe with the times.

It can be seen from Figure 8 that although there is unevenness in the temperature rise of the inner and outer walls in the pipe, the difference in temperatures between the inner and outer walls tends to be stable as the increase of heating time. Therefore, by parameter optimization, the difference in temperature gradient between the inner and outer walls of the pipe is reduced as much as possible.

In order to further explore the relationship between the current frequency, current density, air gap, and pipe heating effect, the control variable method is used to change the three process parameters for simulation calculation. The results are shown in Figure 9.

Figure 9 shows the effect of the current frequency, current density, and the air gap between coil and pipe on the temperature rise of the inner and outer wall of the pipe, respectively. It can be seen from the figure although that relationship between the variation of parameters and the temperature of the inner and outer wall of the pipe is basically linear; the influence of three parameters on the heating effect of pipe cannot be quantified. Moreover, the temperature difference between the inner and outer wall of the pipe is the key quantity; thus it is necessary to analyze the variation rule of the temperature difference between the inner and outer wall of the pipe to find the optimal parameter group.

\subsection{Parameter Optimization Based on Orthogonal Test Design}

3.2.1. Orthogonal Test Design for Induction Heating of Pipe. The three process parameters of the current frequency, 


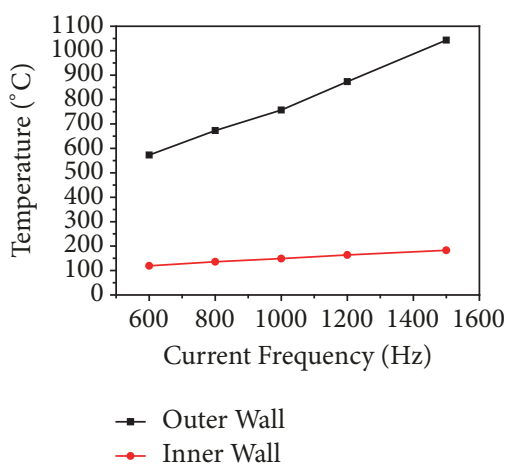

(a)

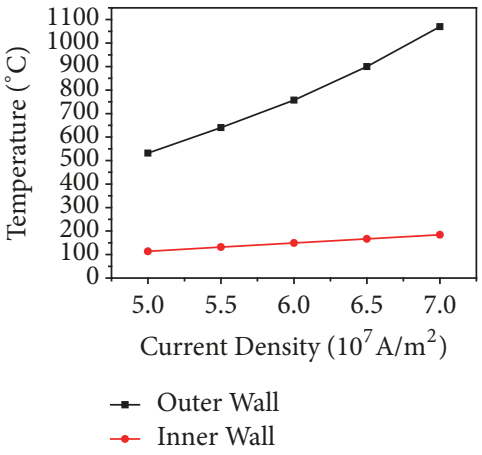

(b)

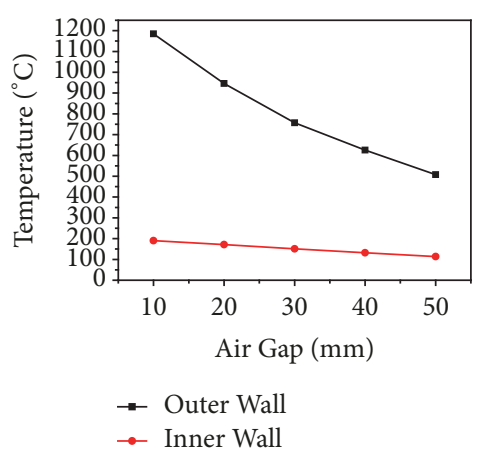

(c)

FIGURE 9: Relationship between three parameters and the inner and outer wall temperature of pipe. (a) Current frequency. (b) Current density. (c) Air gap between pipe and induction coil.

TABLE 2: Test parameters and levels.

\begin{tabular}{|c|c|c|c|}
\hline \multirow[b]{2}{*}{ Level } & \multicolumn{3}{|c|}{ Factor } \\
\hline & $\begin{array}{c}\text { Current Frequency } \\
f(\mathrm{~Hz})\end{array}$ & $\begin{array}{c}\text { Current Density } \\
J\left(\mathrm{~A} / \mathrm{m}^{2}\right)\end{array}$ & $\begin{array}{l}\text { Air Gap } \\
d(\mathrm{~mm})\end{array}$ \\
\hline 1 & 600 & $5 \times 10^{7}$ & 10 \\
\hline 2 & 800 & $5.5 \times 10^{7}$ & 20 \\
\hline 3 & 1000 & $6 \times 10^{7}$ & 30 \\
\hline 4 & 1200 & $6.5 \times 10^{7}$ & 40 \\
\hline 5 & 1500 & $7 \times 10^{7}$ & 50 \\
\hline
\end{tabular}

current density, and air gap are the factors of the orthogonal test [21], and each factor is set at 5 levels, as shown in Table 2.

It can be seen from Table 2 that there is a total of 125 experimental parameter combinations, and the orthogonal test is mainly used to analyze the primary and secondary relationship of the influence of various process parameters on the heating effect. Therefore, according to the orthogonality and the engineering practice, some parameter groups with the characteristics of "uniform dispersion, neatness, and comparability" are selected as the representative ones for the experiment.

In the orthogonal experimental analysis, the Taguchi design method is used to neglect the interaction between different process parameters, the L25 $\left(5^{6}\right)$ orthogonal table is selected, and the empty column is adopted as the error column. According to the 25 sets of parameters selected in Table 3, the numerical simulation analysis of the induction heating of $X 80$ pipe $(\Phi 1219 \mathrm{~mm}$, wall thickness $27 \mathrm{~mm})$ is carried out to obtain the temperatures of the inner and outer walls of the pipe. The orthogonal experimental scheme is designed with the temperatures of the inner and outer walls of the pipe as the test indexes (see Table 3 ).

3.2.2. Analysis of the Orthogonal Test Results of Induction Heating of Pipe. The variance method is used to determine the significant degree and contribution rate of the influence of various process parameters on the heating effect of mediumfrequency induction heating of large-diameter pipes, and the primary and secondary relationship of the influence of various process parameters on the heating effect is obtained. Then we use the range analysis to verify the primary and secondary relationships again to provide a guidance for engineering process design.

(1) Variance Analysis. The analysis results of the influence of each parameter on temperatures of the inner and outer walls of the pipe are shown in Tables 4 and 5.

(2) Range Analysis. First, the comprehensive mean and range of each factor are obtained, and then the primary and secondary relationships of the influence of the process parameters on the heating effect are got by comparing the extremes [22]. The range analysis of the inner and outer wall temperatures of the pipe under different levels in the orthogonal test is shown in Table 6:

According to the analysis results of Tables 4 and 5, when the temperature of the inner and outer walls of the pipe is taken as an index, the influence of the current frequency and current density on the index is significant, and the influence of the air gap on the index is extremely significant. And in the medium-frequency induction heating of the pipe, the influential degree of each process parameter on the heating effect of the pipe is air gap>current density>current frequency. From the range $\mathrm{R}$ corresponding to each process parameter in Table 6, it can be concluded that the influential degree of the process parameters on the heating effect of the pipe is consistent with the variance analysis result, which further verifies the accuracy of the obtained results. Compared with the range analysis, the contribution rate of each process parameter to the survey indicators is defined more clearly by the variance analysis.

It can be known from the engineering that when the induction heating temperatures of the outer wall of the pipe are $900 \sim 1000^{\circ} \mathrm{C}[23]$ and the difference between the inner and outer wall temperature is small, the final processing quality of the elbow is better. Combined with the above analysis, a better process parameter group can be initially determined as current frequency $1500 \mathrm{~Hz}$, current density $5.5 \times 10^{7} \mathrm{~A} / \mathrm{m}^{2}$, and air gap $10 \mathrm{~mm}$. 
TABLE 3: Orthogonal test design scheme and numerical calculation results.

\begin{tabular}{|c|c|c|c|c|c|}
\hline \multirow[b]{2}{*}{ Test No. } & \multicolumn{3}{|c|}{ Factor } & \multicolumn{2}{|c|}{ Test Index } \\
\hline & $\begin{array}{c}\text { Current } \\
\text { Frequency }(\mathrm{Hz})\end{array}$ & $\begin{array}{l}\text { Current Density } \\
\qquad\left(\mathrm{A} / \mathrm{m}^{2}\right)\end{array}$ & $\begin{array}{l}\text { Interval } \\
(\mathrm{mm})\end{array}$ & $\begin{array}{c}\text { Outer Wall } \\
\text { Temperature } \\
\left({ }^{\circ} \mathrm{C}\right)\end{array}$ & $\begin{array}{c}\text { Inner Wall } \\
\text { Temperature } \\
\left({ }^{\circ} \mathrm{C}\right)\end{array}$ \\
\hline 1 & $1(600)$ & $1\left(5 \times 10^{7}\right)$ & $1(10)$ & 649 & 127 \\
\hline 2 & $1(600)$ & $2\left(5.5 \times 10^{7}\right)$ & $2(20)$ & 618 & 125 \\
\hline 3 & $1(600)$ & $3\left(6 \times 10^{7}\right)$ & $3(30)$ & 574 & 119 \\
\hline 4 & $1(600)$ & $4\left(6.5 \times 10^{7}\right)$ & $4(40)$ & 528 & 114 \\
\hline 5 & $1(600)$ & $5\left(7 \times 10^{7}\right)$ & $5(50)$ & 474 & 105 \\
\hline 6 & $2(800)$ & $1\left(5 \times 10^{7}\right)$ & $2(20)$ & 587 & 121 \\
\hline 7 & $2(800)$ & $2\left(5.5 \times 10^{7}\right)$ & $3(30)$ & 569 & 120 \\
\hline 8 & $2(800)$ & $3\left(6 \times 10^{7}\right)$ & $4(40)$ & 546 & 117 \\
\hline 9 & $2(800)$ & $4\left(6.5 \times 10^{7}\right)$ & $5(50)$ & 508 & 113 \\
\hline 10 & $2(800)$ & $5\left(7 \times 10^{7}\right)$ & $1(10)$ & 1526 & 215 \\
\hline 11 & $3(1000)$ & $1\left(5 \times 10^{7}\right)$ & $3(30)$ & 532 & 114 \\
\hline 12 & $3(1000)$ & $2\left(5.5 \times 10^{7}\right)$ & $4(40)$ & 528 & 115 \\
\hline 13 & $3(1000)$ & $3\left(6 \times 10^{7}\right)$ & $5(50)$ & 508 & 113 \\
\hline 14 & $3(1000)$ & $4\left(6.5 \times 10^{7}\right)$ & $1(10)$ & 1420 & 208 \\
\hline 15 & $3(1000)$ & $5\left(7 \times 10^{7}\right)$ & $2(20)$ & 1349 & 205 \\
\hline 16 & $4(1200)$ & $1\left(5 \times 10^{7}\right)$ & $4(40)$ & 509 & 112 \\
\hline 17 & $4(1200)$ & $2\left(5.5 \times 10^{7}\right)$ & $5(50)$ & 508 & 114 \\
\hline 18 & $4(1200)$ & $3\left(6 \times 10^{7}\right)$ & $1(10)$ & 1319 & 201 \\
\hline 19 & $4(1200)$ & $4\left(6.5 \times 10^{7}\right)$ & $2(20)$ & 1297 & 202 \\
\hline 20 & $4(1200)$ & $5\left(7 \times 10^{7}\right)$ & $3(30)$ & 1248 & 200 \\
\hline 21 & $5(1500)$ & $1\left(5 \times 10^{7}\right)$ & $5(50)$ & 510 & 115 \\
\hline 22 & $5(1500)$ & $2\left(5.5 \times 10^{7}\right)$ & $1(10)$ & 989 & 173 \\
\hline 23 & $5(1500)$ & $3\left(6 \times 10^{7}\right)$ & $2(20)$ & 1255 & 200 \\
\hline 24 & $5(1500)$ & $4\left(6.5 \times 10^{7}\right)$ & $3(30)$ & 1253 & 202 \\
\hline 25 & $5(1500)$ & $5\left(7 \times 10^{7}\right)$ & $4(40)$ & 1239 & 204 \\
\hline
\end{tabular}

TABLE 4: Variance analysis results of the orthogonal test of temperatures for pipe's outer wall.

\begin{tabular}{|c|c|c|c|c|c|c|}
\hline $\begin{array}{l}\text { Sources of } \\
\text { Variance }\end{array}$ & $\begin{array}{l}\text { Degree of } \\
\text { Freedom }\end{array}$ & $\begin{array}{l}\text { Sum of } \\
\text { Squares }\end{array}$ & Mean Square & $\mathrm{F}$ & $\begin{array}{c}\text { Contribution } \\
\text { Rate }(\%)\end{array}$ & Significance \\
\hline $\begin{array}{l}\text { Current } \\
\text { Frequency }\end{array}$ & 4 & 0.996 & 0.25 & 31.63 & 21.28 & * \\
\hline $\begin{array}{l}\text { Current } \\
\text { Density }\end{array}$ & 4 & 1.49 & 0.372 & 47.32 & 31.84 & * \\
\hline Air Gap & 4 & 2.1 & 0.525 & 66.68 & 44.86 & $* *$ \\
\hline Error & 12 & 0.095 & 0.008 & - & 2.02 & \\
\hline Total & 24 & 4.671 & 1.155 & - & 100 & \\
\hline
\end{tabular}

Note: $*$ indicates that the difference is significant; $* *$ indicates that the difference is extremely significant.

3.3. Process Parameter Optimization Based on Neural Network and Genetic Algorithm. The orthogonal experiment can determine the influence degree of the process parameters on the temperature of the inner and outer walls of the pipe and judge the better parameter group from the existing process parameter group. However, it is difficult to obtain the global optimal process parameters for the multiparameter group problems which affect the actual engineering. We use BP neural network method to establish the mapping relationship between the induction heating process parameters and the temperatures of the inner and outer walls of the pipe $[24,25]$. The data is trained to predict the heating effect of all combinations of process parameters within the variation range, and the process parameters are optimized by genetic algorithm $[26,27]$. Thus, the global optimal process parameter group is obtained. 
TABLE 5: Variance analysis results of orthogonal test of temperatures for pipe's inner wall.

\begin{tabular}{lccccc}
\hline $\begin{array}{l}\text { Sources of } \\
\text { Variance }\end{array}$ & $\begin{array}{c}\text { Degree of } \\
\text { Freedom }\end{array}$ & $\begin{array}{c}\text { Sum of } \\
\text { Squares }\end{array}$ & Mean Square & F & $\begin{array}{c}\text { Contribution } \\
\text { Rate }(\%)\end{array}$ \\
\hline $\begin{array}{l}\text { Current } \\
\text { Frequency }\end{array}$ & 4 & 0.478 & 0.12 & 37.77 & 25.78 \\
$\begin{array}{l}\text { Current } \\
\text { Density }\end{array}$ & 4 & 0.589 & 0.147 & 46.47 & 31.72 \\
Air Gap & 4 & 0.751 & 0.188 & 59.26 & 40.45 \\
Error & 12 & 0.038 & 0.003 & - & 2.05 \\
Total & 24 & 1.856 & 0.458 & - & 100 \\
\hline
\end{tabular}

Note: $*$ indicates that the difference is significant; $* *$ indicates that the difference is extremely significant.

TABLE 6: Range analysis results of orthogonal test for pipe’s outer wall temperature.

\begin{tabular}{|c|c|c|c|c|c|c|}
\hline & \multicolumn{3}{|c|}{ Outer Wall Temperature $\left({ }^{\circ} \mathrm{C}\right)$} & \multicolumn{3}{|c|}{ Inner Wall Temperature $\left({ }^{\circ} \mathrm{C}\right)$} \\
\hline & $\begin{array}{l}\text { Current } \\
\text { Frequency }\end{array}$ & $\begin{array}{l}\text { Current } \\
\text { Density }\end{array}$ & Air Gap & $\begin{array}{l}\text { Current } \\
\text { Frequency }\end{array}$ & $\begin{array}{l}\text { Current } \\
\text { Density }\end{array}$ & Air Gap \\
\hline$K_{1}$ & 568.6 & 557.4 & 1180.6 & 118 & 117.6 & 184.8 \\
\hline$K_{2}$ & 747.2 & 642.4 & 1021.2 & 137.2 & 129.4 & 170.6 \\
\hline$K_{3}$ & 867.4 & 840.4 & 835.2 & 151 & 150 & 151 \\
\hline$K_{4}$ & 976.2 & 1001.2 & 670 & 165.8 & 167.8 & 132.4 \\
\hline$K_{5}$ & 1049.2 & 1167.2 & 501.6 & 178.8 & 185.8 & 112 \\
\hline$R$ & 480.6 & 609.8 & 679 & 60.8 & 68 & 72.8 \\
\hline
\end{tabular}

Note: $K_{1} \sim K_{5}$ represent the average temperature of each factor at each level, and $R$ is range.

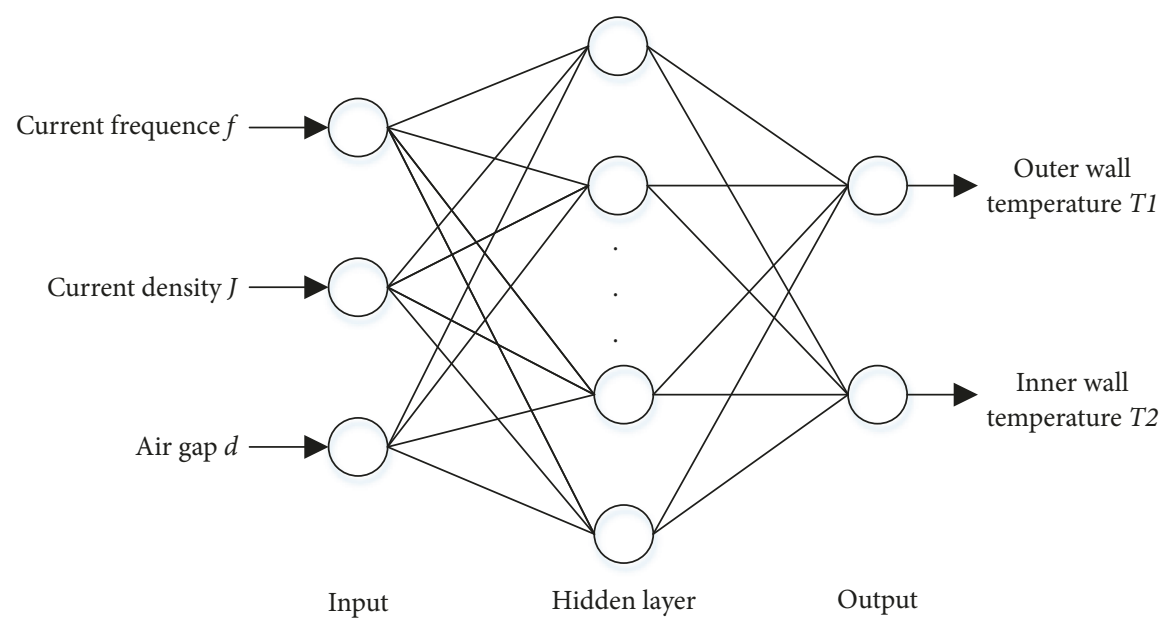

FIGURE 10: Structure of pipe induction heating BP neural network.

3.3.1. Prediction Model Based on BP Neural Network. The current frequency, current density, and air gap are selected as the network model input, and the outer and inner wall temperatures $T_{1}$ and $T_{2}$ of the pipe are taken as output to build a three-layer BP neural network model. The network structure is shown in Figure 10.

The data (see Table 3 ) obtained by numerical simulation is used as a training sample, and the sample is trained by running a BP neural network program. The training target is selected as 0.000001 and the learning rate is 0.1 . The training of the network model is shown in Figure 11. When the iteration is 274 times, the training is finished with the system error of $9.75 \times 10^{-7}$; thus its error is within the expected range, and the network output is more accurate.

In order to verify the accuracy of the training prediction results, the five new sets of process parameters are reselected as test samples for training prediction and numerical simulation. The training prediction results and numerical simulation results are shown in Table 7.

According to the above results in Table 7 , the error between the prediction data and the simulation data is within $3 \%$, which indicates that the prediction accuracy of the BP 
TABLE 7: Error between numerical simulation and BP neural network training.

\begin{tabular}{lccccccc}
\hline Current Frequency & Current Density & Air Gap & \multicolumn{2}{c}{ Outer Wall Temperature $T_{1}\left({ }^{\circ} \mathrm{C}\right)$} & \multicolumn{3}{c}{ Inner Wall Temperature $T_{2}\left({ }^{\circ} \mathrm{C}\right)$} \\
$f(\mathrm{~Hz})$ & $J\left(\mathrm{~A} / \mathrm{m}^{2}\right)$ & $d(\mathrm{~mm})$ & Simulation & Prediction & Error & Simulation & Prediction \\
\hline 1200 & $6 \times 10^{7}$ & 30 & 883 & 862.5 & $2.3 \%$ & 164 & 163.29 \\
1500 & $6 \times 10^{7}$ & 30 & 1043 & 1036.5 & $0.62 \%$ & 183 & 185.35 \\
1000 & $5.5 \times 10^{7}$ & 30 & 640 & 638.2 & $0.28 \%$ & 132 & 130.67 \\
1000 & $6.5 \times 10^{7}$ & 30 & 900 & 894.5 & $0.61 \%$ & 167 & 163.40 \\
1000 & $7 \times 10^{7}$ & 30 & 1070 & 1079.3 & $0.87 \%$ & 184 & 180.71 \\
\hline
\end{tabular}

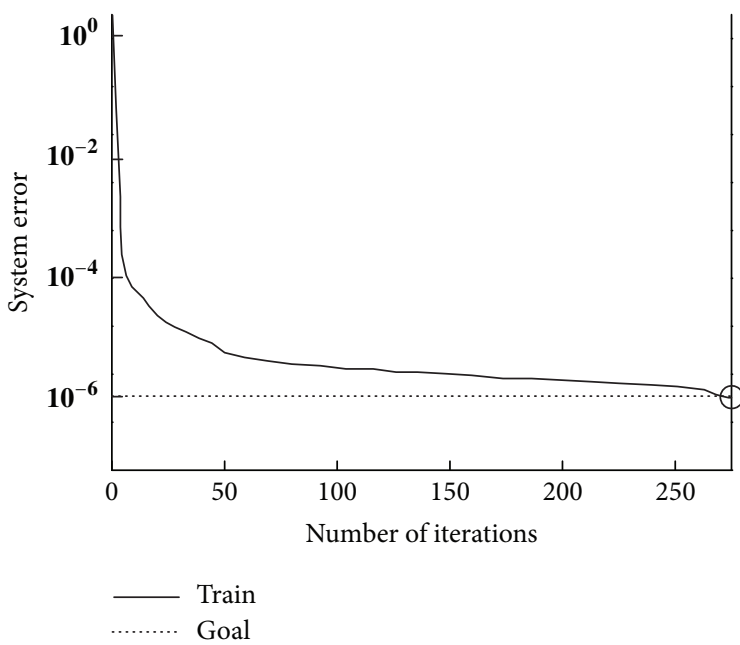

FIGURE 11: BP neural network training error curve.

neural network for the heating effect is higher, and the prediction result is close to the actual situation.

\subsubsection{Optimization of Induction Heating Parameters Based} on Genetic Algorithm. The population with a size of 50 is selected and the binary code is adopted. The crossover probability and mutation probability are 0.75 and 0.01 , respectively. The BP neural network prediction result is used as the fitness function to control the temperature of the inner and outer walls of the pipe $[28,29]$. The genetic algorithm with 100 times of iteration is designed to optimize the process parameters of pipe induction heating. The software is used to iteratively calculate the BP neural network and genetic algorithm joint optimization program. After 100 iterations, the target fitness is shown in Figure 12.

It can be seen from the Figure 12 that, after 30 iterations, the fitness value of the temperature difference between the inner and outer wall under the processable condition is maintained at 751; meanwhile the temperature $T_{1}$ of the outer wall and the temperature $T_{2}$ of the inner wall is $923^{\circ} \mathrm{C}$ and $172^{\circ} \mathrm{C}$, respectively. The process parameter group that is superior to the orthogonal test in the induction heating process of the pipe is obtained with the current frequency, current density, and air gap which are $1460 \mathrm{~Hz}, 5.65 \times$ $10^{7} \mathrm{~A} / \mathrm{m}^{2}$, and $15 \mathrm{~mm}$, respectively.

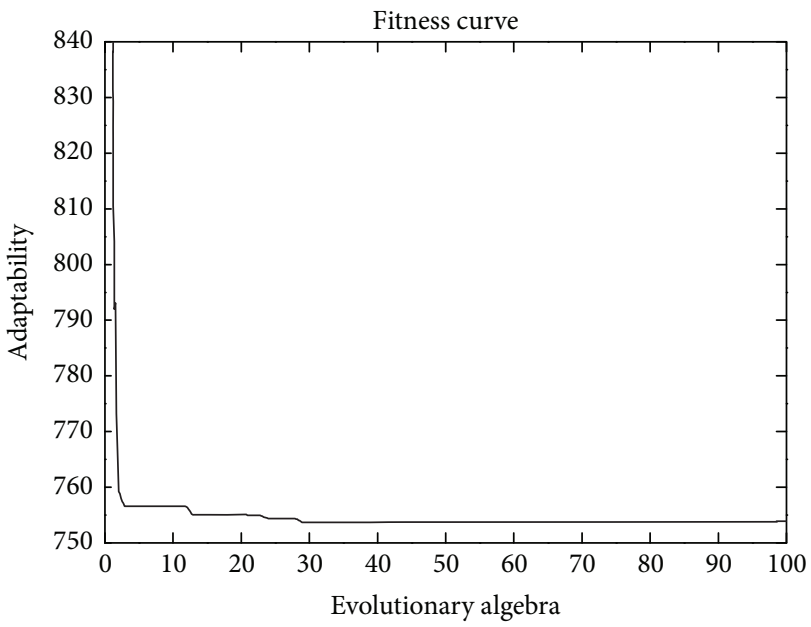

FIGURE 12: Genetic algorithm optimization process.

3.4. Pipeline Induction Heating Prediction Model Based on Regression Analysis. Through the aforementioned analysis and calculation, the selection of optimal parameter group for the induction heating parameter design can be realized, but In order to further guide the engineering practice, a prediction model of pipe induction heating is necessary. In this paper, the regression analysis of the data obtained from numerical simulation is carried out to determine a reasonable mathematical model for the prediction of the outer wall temperature, which provides a certain theoretical guidance for the actual processing. The data obtained from the numerical simulation of medium-frequency induction heating of large-diameter pipe are taken as samples, and the process parameters that influence the induction heating effect of pipe materials, such as current frequency $f(\mathrm{~Hz})$, current density $J\left(\mathrm{~A} / \mathrm{m}^{2}\right)$, and air gap $d(\mathrm{~mm})$, are seen as independent variables, while the outer wall temperature of the pipe is seen as the dependent variable. Subsequently, two regression models are established for prediction of the pipe outer wall temperature $T$ on the basis of combining the feature of sample data. It can be seen from Figure 9 that the process parameters and the temperature of the inner and outer walls show a linear change law; thereby a regression Model I is established. However, considering the magnitude difference of the selected values of each parameter, 
TABLE 8: Results of regression analysis.

\begin{tabular}{lcc}
\hline & Model I: $T=b_{0} f+b_{1} J+b_{2} d+C$ & Model II: $T=C f^{b_{0}} J^{b_{1}} d^{b_{2}}$ \\
\hline Regression Coefficients & $\left(0.525,3.092 \times 10^{-5},-17.184,-1049.604\right)$ & $(-33.103,0.642,2.061,-0.481)$ \\
Sum of Residuals & 181575.2825 & 0.295 \\
Return Square Sum & 3712511.687 & 4.915 \\
Correlation Coefficient & 0.953 & 0.943 \\
$\mathrm{r}^{2}$ & 129.515 & 120.585 \\
F-test Value & $1.029 \times 10^{-20}$ & $2.23 \times 10^{-19}$ \\
$\mathrm{P}$ & & \\
\hline
\end{tabular}

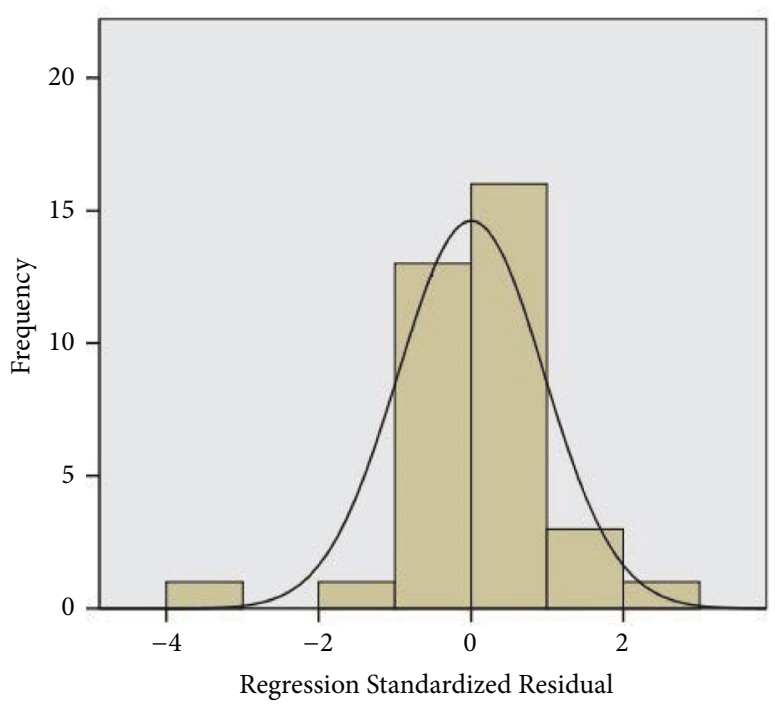

(a) Model I

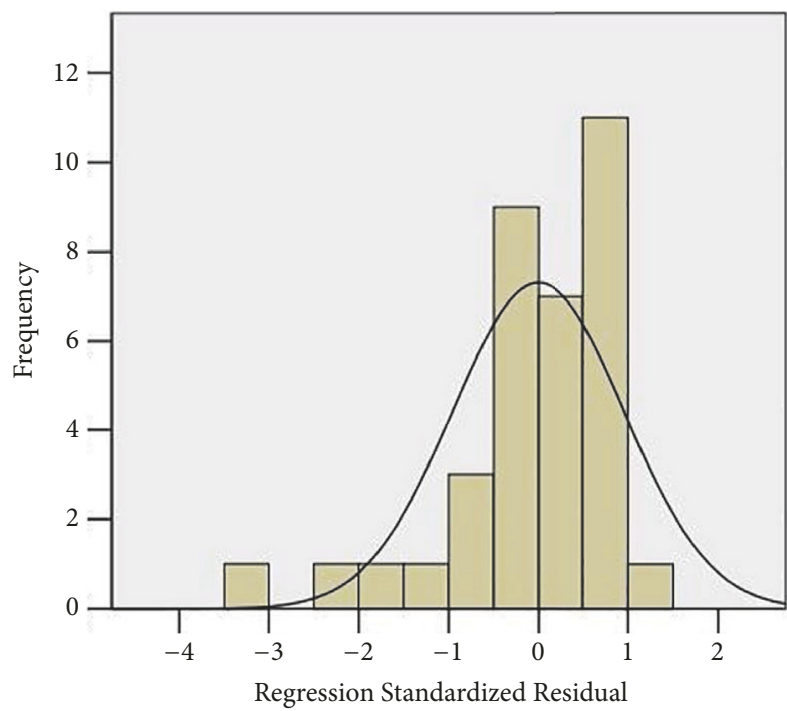

(b) Model II

FIGURE 13: Regression standardized residual histogram.

the logarithmic conversion of the sample data is performed to build a regression Model II [30].

$$
\begin{aligned}
& \text { Regression Model I: } T=b_{0} f+b_{1} J+b_{2} d+C \\
& \text { Regression Model II: } T=C f^{b_{0}} J^{b_{1}} d^{b_{2}}
\end{aligned}
$$

Assume that the above two regression models meet the following conditions:

(1) $\varepsilon_{i} \sim N\left(0, \sigma_{2}\right), \operatorname{Cov}\left(\varepsilon_{i}, \varepsilon_{j}\right)=0, i \neq j$

(2) The selected variables are not random and have no multiple linear relationship with each other

(3) There is a linear relationship between the dependent variable $T$ and the transformed independent variable in the regression model II

The two regression models are analyzed and solved by a multiple regression calculation program, and the results are shown in Table 8.

The regression equations obtained by stepwise regression calculation are as follows:

Equation of Model I: $T=0.525 f+3.092 \times$ $10^{-5} J-17.184 d-1049.604$

Equation of Model II: $T=e^{-33.103} f^{0.642} J^{2.061} d^{-0.481}$
It can be seen from Figure 13 that although the normalized residuals of Model I and Model II are basically normal distribution, comprehensive analysis of the calculation results of Table 8, including the correlation coefficient, sum of squared residuals, and F-test value. It can been seen that Model I has an optimal fitting degree; thus the regression equation (1) is chosen as the mathematical model for predicting the outer wall temperature of large-diameter pipe during the mediumfrequency induction heating. In order to verify the accuracy of the regression models, five sets of process parameters are taken as test samples for the numerical simulation and regression model prediction. The results are shown in Table 9.

It can be seen from Table 9 that errors between the simulated data and predicted data are within 5\%. The error value needs to be determined according to industry standards. However, it is worth noting that the mathematical model of the outer wall temperature prediction can accurately reflect the mapping relationship between the process parameters of the induction heating and the outer wall temperatures of the pipe. The mathematical model of the outer wall temperature prediction for large-diameter pipe in the induction heating process has certain significance for guiding engineering practice. 
TABLE 9: Errors between the numerical simulation and regression model prediction.

\begin{tabular}{|c|c|c|c|c|c|}
\hline \multirow{2}{*}{$\begin{array}{l}\text { Current Frequency } \\
f(\mathrm{~Hz})\end{array}$} & \multirow{2}{*}{$\begin{array}{c}\text { Current Density } \\
J\left(\mathrm{~A} / \mathrm{m}^{2}\right)\end{array}$} & \multirow{2}{*}{ Air Gap $d(\mathrm{~mm})$} & \multicolumn{3}{|c|}{ Outer Wall Temperature $T\left({ }^{\circ} \mathrm{C}\right)$} \\
\hline & & & Simulation & Return & Error \\
\hline 1200 & $6 \times 10^{7}$ & 30 & 883 & 920.1 & $4.2 \%$ \\
\hline 1500 & $6 \times 10^{7}$ & 30 & 1043 & 1077.6 & $3.2 \%$ \\
\hline 1000 & $5.5 \times 10^{7}$ & 30 & 640 & 660.5 & $3.1 \%$ \\
\hline 800 & $6 \times 10^{7}$ & 30 & 683 & 710.1 & $4.0 \%$ \\
\hline 1000 & $6 \times 10^{7}$ & 40 & 626 & 643.2 & $2.7 \%$ \\
\hline
\end{tabular}

\section{Conclusions}

(1) Based on the basic theory of induction heating and analysis of induction heating forming process for largediameter $X 80$ pipe, the magnetic-thermal coupling issue in the heating process is simulated by sequential coupling method. The influential law of each group's induction heating process parameters (current frequency, current density, and air gap) on the temperature of the inner and outer walls of the pipe has been obtained.

(2) Taking the induction heating process parameters as the test factors, we carry out the orthogonal test design of the process parameters with the difference of the inner and outer wall temperature of the pipe as the evaluation index, the influential degree of each process parameter on the heating effect is determined as air gap >current density $>$ current frequency, and the optimized process parameter sets for the heating bending of the pipe have been obtained using the neural network genetic algorithm, with the current frequency, current density, and air gap which are $1460 \mathrm{~Hz}$, $5.65 \times 10^{7} \mathrm{~A} / \mathrm{m}^{2}$, and $15 \mathrm{~mm}$, respectively.

(3) The linear regression models of two types of pipe temperature have been built based on the simulation results of different heating parameters. By comparing and analyzing the relevant test standards of each regression equation, we have obtained the mathematical model of the outer wall temperature prediction during the induction heating process of the pipe.

(4) From the bend forming practice of $X 80$ pipe, the numerical simulation process parameters sets are somewhat limited. Hopefully, our mathematical analysis method is of a referential significance for practical engineering.

\section{Data Availability}

The data used to support the findings of this study are available from the corresponding author upon request.

\section{Conflicts of Interest}

The authors declare that they have no conflicts of interest.

\section{Acknowledgments}

This work was supported by National Natural Science Foundation of China (NSFC) (no. 51775427)

\section{References}

[1] R. X. Fang and W. S. Cao, "The research of hydraulic technology for large caliber medium frequency heating pipe hydraulic bending machine," Chinese Hydraulics \& Pneumatics, 2010.

[2] X. Fang, J. Wang, and W. Cao, "Induction heating of largediameter thin-walled elbow based on skin effect," Oil \& Gas Storage and Transportation, vol. 36, no. 8, pp. 958-963, 2017.

[3] X. Fang, X. Meng, and H. Fan, "Research on Ultra-low and Constant Speed Hydraulic Control System of Large Pushbending Style Pipe Bender," Machine Tool \& Hydraulics, vol. 19, pp. 61-64, 2017.

[4] C. Pandey, M. M. Mahapatra, P. Kumar, N. Saini, and J. G. Thakre, "Nano-size Particle Evolution During Heat Treatment of P91 Steel and Their Effect on Micro Hardness," Transactions of the Indian Institute of Metals, pp. 1-8, 2017.

[5] C. Pandey and M. M. Mahapatra, "Effect of Heat Treatment on Microstructure and Hot Impact Toughness of Various Zones of P91 Welded Pipes," Journal of Materials Engineering and Performance, vol. 25, no. 6, pp. 2195-2210, 2016.

[6] C. Zheng, H. Liu, X. Ding, and Q. Fu, "Horizontal Vibration of a Large-Diameter Pipe Pile in Viscoelastic Soil," Mathematical Problems in Engineering, vol. 2013, Article ID 269493, 13 pages, 2013.

[7] C. Pandey, M. Mahapatra, P. Kumar et al., "Some studies on P91 steel and their weldments," Journal of Alloys \& Compounds, vol. 743, pp. 332-364, 2018.

[8] S. Q. Pan, X. U. Zhe, and H. E. Bi-Shi, "A Study on Temperature Control for the Billet Electromagnetic Induction Heating Based on Simulation," Industrial Heating, vol. 41, no. 6, pp. 25-28, 2012.

[9] H. Du, J. Li, and Y. Qu, "Mathematical Modeling of EddyCurrent Loss for a New Induction Heating Device," Mathematical Problems in Engineering, vol. 2014, Article ID 923745, 7 pages, 2014.

[10] Y. Wang, C. Liu, and X. Wang, "Influence of induction coil parameter on temperature field of steel plate and choosing of coil size," Jinshu Rechuli/Heat Treatment of Metals, vol. 41, no. 4, pp. 178-182, 2016.

[11] T. D. S. Antonino, P. B. Guimarães, R. D. A. Alécio et al., "Measurements of the Thermophysical Properties of the API 5L X80," Materials Sciences \& Applications, vol. 5, no. 8, pp. 617-627, 2014.

[12] Y. H. Zhang, Numerical Simulation of Induction Heating Temperature Field, Jiangnan University, 2008.

[13] Z. QianZhe, Numerical Simulation and Experimental Study on Induction Heating Process of Steel Bar Production Line, North China Electric Power University, 2013. 
[14] Z. Tianxu, Numerical analysis and experimental study on dynamic medium frequency induction heating process of high frequency straight seam welded pipe, Yanshan University, 2016.

[15] Y. Chenguang, Numerical Simulation of Variable Power Induction Heating of 42CrMo Steel Shaft Parts, Yanshan University, 2010.

[16] S. Wenjie, Numerical simulation and experimental study on electromagnetic field and temperature field of large-diameter molten silicon single crystal growth equipment, Zhejiang University, 2013.

[17] J. L. Fleming and J. Moser, "A Fourier Approach to Model Electromagnetic Fields Scattered by a Buried Rectangular Cavity," Mathematical Problems in Engineering, vol. 2009, Article ID 937327, 22 pages, 2009.

[18] X. Yi, L. Li, J. Yue et al., "Simulation of coupling of electromagnetic and thermal of intermediate frequency induction heating of pipeline," Heat Treatment of Metals, vol. 41, no. 7, pp. 154-158, 2016.

[19] H. U. Jun, J. Chen, and L. I. Ming, "Research on Drawing Technology of High-strength Steel Rectangular Box Based on ABAQUS," Hot Working Technology, 2014.

[20] S. Liu, H. Shi, and L. Feng, “Transformer harmonic loss model considering skin effect and proximity effect," Dianli Zidonghua Shebei/Electric Power Automation Equipment, vol. 35, no. 3, pp. 133-139, 2015.

[21] Z. Zhao and S.-Y. Zhang, "Self-adaptive step sequentialinteraction method and its application in transient-fields coupling problems," Jisuanji Jicheng Zhizao Xitong/Computer Integrated Manufacturing Systems, CIMS, vol. 17, no. 7, pp. 14041414, 2011.

[22] Z. Wang, W. Yang, and Y. Song, "The R/S analysis and application in the oil-gas gathering and transportation process," Petroleum Exploration \& Development, vol. 37, no. 5, pp. 618622, 2010

[23] C. Pandey, A. Giri, and M. M. Mahapatra, "Evolution of phases in P91 steel in various heat treatment conditions and their effect on microstructure stability and mechanical properties," Materials Science \& Engineering A, vol. 664, pp. 58-74, 2016.

[24] S. Wang, N. Zhang, L. Wu, and Y. Wang, "Wind speed forecasting based on the hybrid ensemble empirical mode decomposition and GA-BP neural network method," Journal of Renewable Energy, vol. 94, pp. 629-636, 2016.

[25] Z. Sun, H. Yang, and Z. Tang, "Microstructural evolution model of TA15 titanium alloy based on BP neural network method and application in isothermal deformation," Computational Materials Science, vol. 50, no. 2, pp. 308-318, 2010.

[26] C. Bharathi, D. Rekha, and V. Vijayakumar, "Genetic Algorithm Based Demand Side Management for Smart Grid," Wireless Personal Communications, vol. 93, no. 2, pp. 481-502, 2017.

[27] H. S. Madraswala and A. S. Deshpande, "Genetic algorithm solution to unit commitment problem," in Proceedings of the 2017 International Conference on Nascent Technologies in Engineering, ICNTE 2017, India, January 2017.

[28] S. Pal, S. K. Pal, and A. K. Samantaray, "Artificial neural network modeling of weld joint strength prediction of a pulsed metal inert gas welding process using arc signals," Journal of Materials Processing Technology, vol. 202, no. 1-3, pp. 464-474, 2008.

[29] J. Tang, "Study on temperature control effect with pipe-cooling of thick inverted T-shaped concrete pier-wall during construction," Water Resources \& Hydropower Engineering, 2017.
[30] C. Pandey, A. Giri, and M. M. Mahapatra, "On the prediction of effect of direction of welding on bead geometry and residual deformation of double-sided fillet welds," International Journal of Steel Structures, vol. 16, no. 2, pp. 333-345, 2016. 


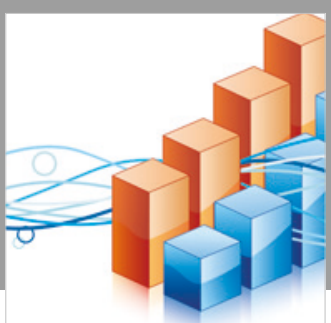

Advances in

Operations Research

\section{-n-m}
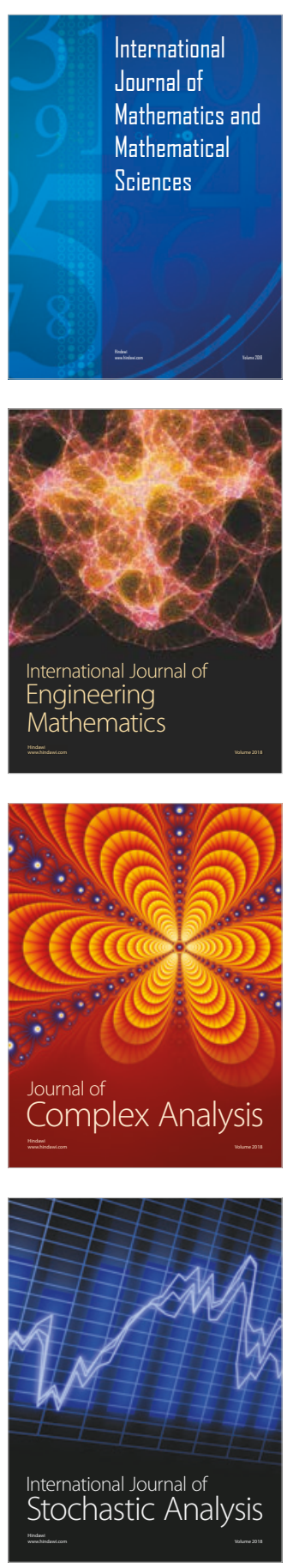
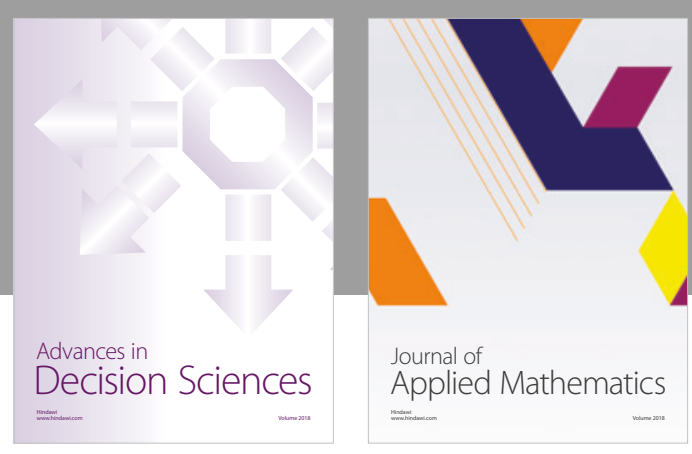

Journal of

Applied Mathematics
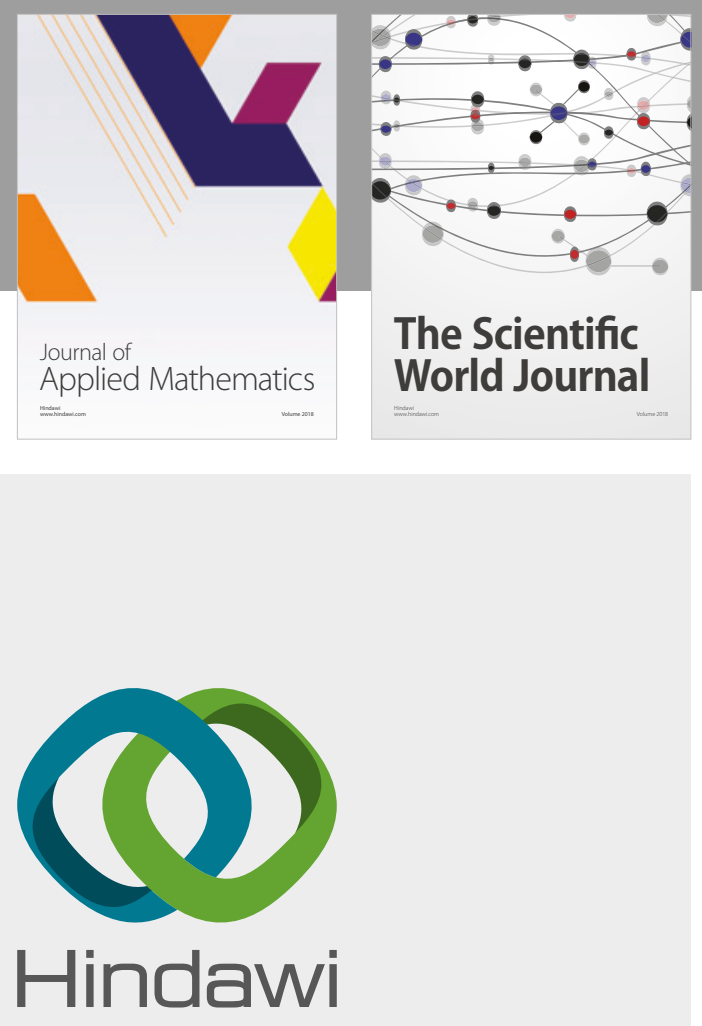

Submit your manuscripts at

www.hindawi.com

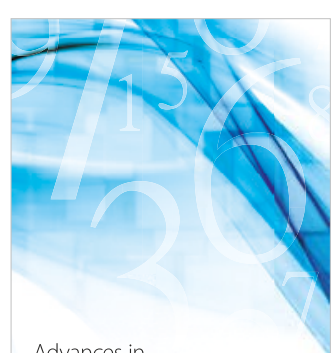

Advances in
Numerical Analysis
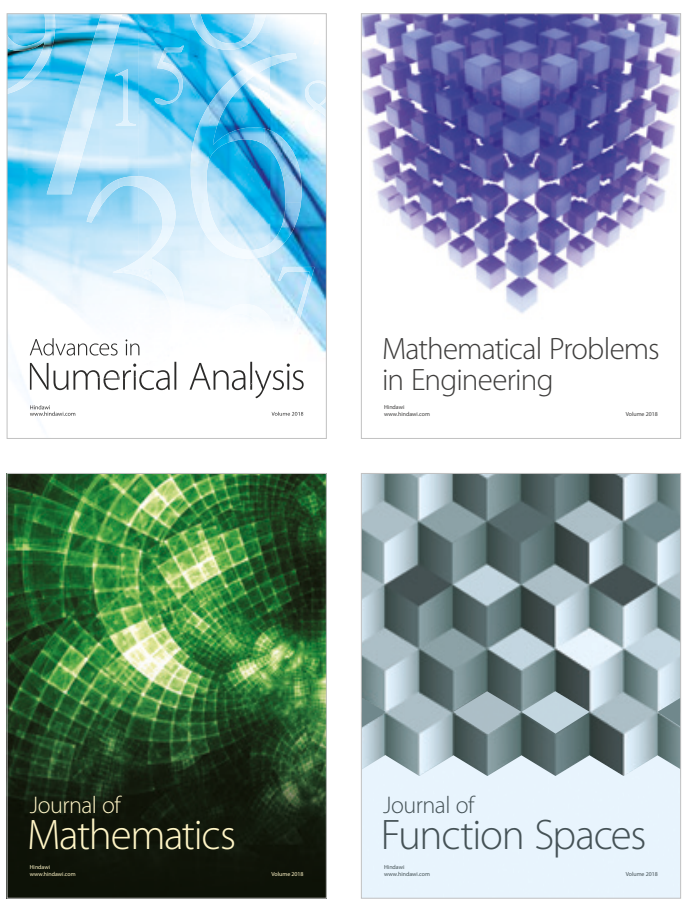

Mathematical Problems in Engineering

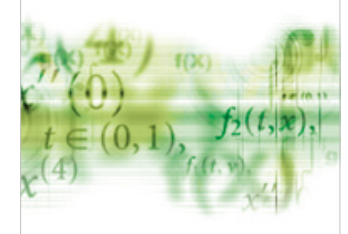

International Journal of

Differential Equations

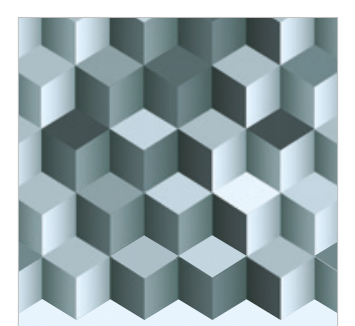

Journal of

Function Spaces

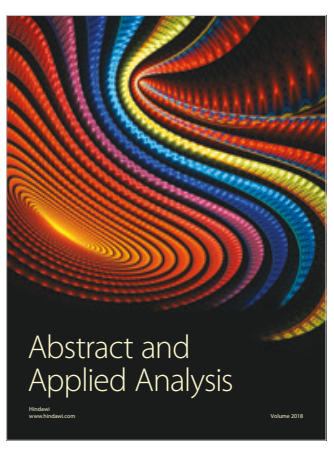

The Scientific

World Journal

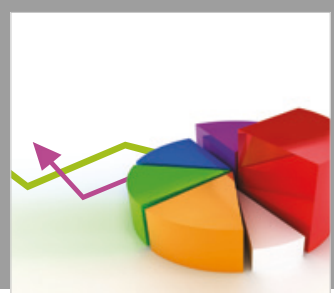

Journal of

Probability and Statistics
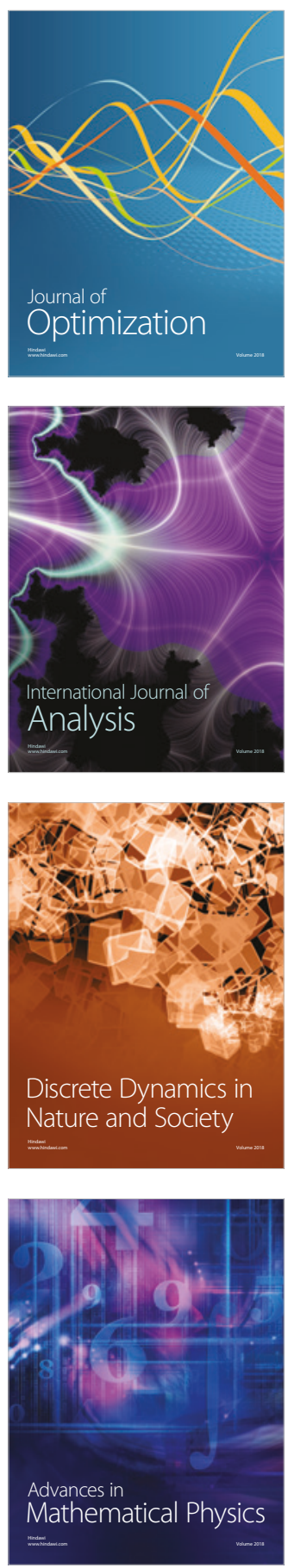